\title{
Smart Water Quality Monitoring System Design and KPIs Analysis: Case Sites of Fiji Surface Water
}

\author{
K. A. Mamun ${ }^{1}$, F. R. Islam ${ }^{2, *}$, R. Haque ${ }^{2}\left(\mathbb{D}\right.$, M. G. M. Khan ${ }^{3} \odot$, A. N. Prasad ${ }^{1}$, H. Haqva ${ }^{1}$, \\ R. R. Mudliar ${ }^{1}$ and F. S. Mani ${ }^{4}$ \\ 1 School of Engineering and Physics, The University of the South Pacific, Suva, Fiji; \\ kabir.mamun@usp.ac.fj (K.A.M.); prasad_a@student.usp.ac.fj (A.N.P.); haqva_h@student.usp.ac.fj (H.H.); \\ mudliar_r@student.usp.ac.fj (R.R.M.) \\ 2 School of Science and Engineering, University of the Sunshine Coast, Queensland 4556, Australia; \\ rhaque@usc.edu.au \\ 3 School of Computing, Information and Mathematical Sciences, The University of the South Pacific, Suva, Fiji; \\ khan_mg@usp.ac.fj \\ 4 School of Biological and Chemical Sciences, The University of the South Pacific, Suva, Fiji; \\ francis.mani@usp.ac.fj \\ * Correspondence: fislam@usc.edu.au
}

Received: 22 August 2019; Accepted: 6 December 2019; Published: 11 December 2019

check for updates

\begin{abstract}
Over recent years, waters in and around Fiji has increasingly succumbed to a reasonable level of contamination. Water quality is defined with set of standards that clearly state the parameters of different properties in water. These standards are different at various geographic locations. The specific quantitative values of these parameters for the Fiji Islands are established by the Fiji National Drinking Water Quality Standards (FNDWQS). Fiji is geographically located in the vast Pacific Ocean, and requires a data collection framework for different water parameters to monitor water quality. The GIS framework system can effectively solve this continuously in real-time. With the end goal being to quantify different parameters; four (04) key performance indicators (KPI) are identified: Temperature, potential of hydrogen $(\mathrm{pH})$, Oxidation Reduction Potential (ORP), and Conductivity. This paper presents a Smart Water Quality Monitoring System (SWQMS) which has been developed and deployed in five (05) Fijian locations (nodes) for the aforementioned KPIs measurement. The SWQMS interfaced with GIS and were powered using solar based Renewable Energy Source (REs). Finally, obtained data were tested and analyzed using statistical methods and verified comparing with the FNDWQS. The findings demonstrated that the system is capable of delivering an accurate and consistent measurement of water quality in real-time. Hence SWQMS could be a smart choice for various Pacific Island Countries (PICs) to use to monitor the water quality and in turn develop sustainable cities and societies.
\end{abstract}

Keywords: GIS; sensor data; water quality; pacific region; renewable energy; sustainable cities

\section{Introduction}

Environmental and ecological changes have put various marine species at risk of extermination and poses a real threat to biodiversity. Several species in coastal areas are vulnerable to climate change and environmental pollution. Similar circumstances are also applicable for human beings. Frequent monitoring and observation of various water parameters are required to maintain the high water quality levels that are necessary for living beings. An appropriate range for various water parameters can be identified as a key performance indicator (KPI), for the water quality, particularly for a geographic location [1-3]. Water is an unavoidable requirement of livelihood for billions of 
people all over the world, due to industrialization, the massive growth in population, excessive use of chemicals for agricultural activities, reclamation of land, and oil spillage into the water, and it is being contaminated at an alarming rate which is now a matter of concern. Therefore, it is important to monitor and test water quality real-time on a regular basis to take necessary steps in order to reduce water pollution and control the quality of water whenever it is necessary. The accessibility of quality water is essential for disease control and for enhancing health.

Natural impurities caused by weathering and the decay of marine organisms and various manmade activities introduce impurities in the water, like iron, lead, chromium, and even radioactive uranium $[4,5]$. A set of standards for both surface and drinking water which are established and regulated by the authority of a country, clearly state the limits of the potential of hydrogen $(\mathrm{pH})$, dissolved oxygen (DO), alkalinity, ORP, conductivity, and salinity to maintain a high quality of water. Standards are different from country to country due to differing geographical locations [6]; however, a standard is not yet well established for Fiji. Henceforward, it is necessary to classify and define the exact values of the parameters for various sources of water available here in Fiji, and this case study will partially address this issue. The Fiji National Drinking Water Quality Standards (FNDWQS) [3] state that the frequency of measurement for water parameters of the local water supply occur be on a daily basis, which is currently being conducted using portable/mobile testing tools or by the water samples being brought to a central laboratory test water quality parameters, which is obviously not a convenient method. The islands are scattered and therefore there is a need for a robust monitoring device that could provide real-time data and inform stakeholders of any undesired activities impacting on water quality.

The experiment in this research setup has been carried out in Fiji's capital city (Suva) and Sigatoka, due to locality and ease of access. The challenges that lead to the development of such technologies mainly involve the availability of resources in remote places. To conduct water testing in islands with the present situation and technology available here in this country is quite challenging as the samples need to be brought in every hour or two and have analysis performed on them in Suva. In Fiji, there are not many such technologies or devices available that can investigate the quality of water being supplied to each household. While, people can use water filters as a precaution to ensure safe health, this is an expensive approach for persons with normal middle incomes, so the major sources of drinking water in Fiji are either bore-hole or supplied tap water. The Water Authority of Fiji (WAF) normally performs the water quality test before the water is pumped out to the consumers, but there are still uncertainties regarding the water quality on the consumer end side.

Accordingly, there is a requirement for further improvement of a network based, automated, real-time water quality measurement system that can deliver instant information of the local water quality and also help in controlling the quality of water for different applications ranging from aquaculture farmhouses and coastlines to articulated reservoirs. The proposed system in this research has been designed based on Internet of Things (IoT) [7] integrated with a wireless sensor network that is not only able to sense various water quality parameter remotely but also able to investigate and provide water quality KPIs information in real-time progressively utilizing GIS. The fundamental objective of this GIS integration and sensor-based water monitoring system is the automation of the measurement of the KPIs [8] of surface water, resulting in improved reliability and performance. This system will further simplify the respective tasks involved by the various interested parties (i.e., the Water and Environment Management Authority) within the scope of water quality management [9-12]. This proposed system enables automated measurement of KPIs at various sites at regular intervals to have reliable quality assurance. Moreover, this sensor-based GIS integrated Smart Water Quality Monitoring System (SWQMS) helps to monitor water quality from a central workbench and provides access to the information whenever required by the various respective stake holders. Figure 1 shows the schematic of the SWQMS working principle for the experimental setup used here in Fiji to monitor surface water quality during this case study. 
The structure of this article is as follows: Section 2 introduce the KPIs modeling for a specific water quality monitoring system, in Section 3 the proposed SWQMS is illustrated in detail, Section 4 presents the GIS interface design, results and discussion are presented in Section 5, and lastly Section 6 presents the conclusion.

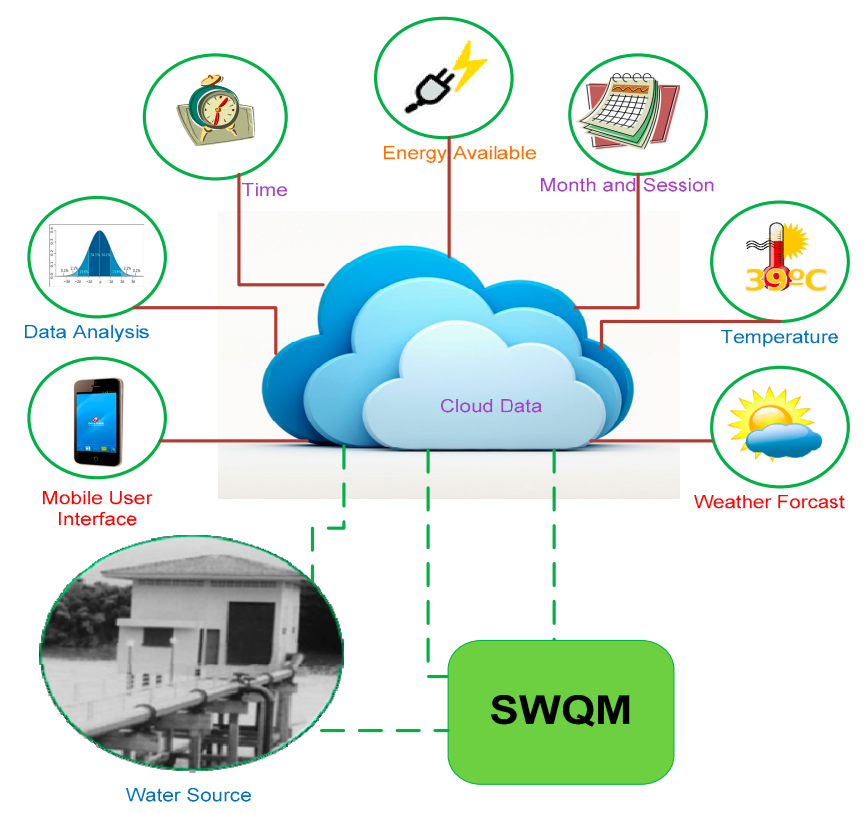

Figure 1. The model in operation.

\section{A KPI Design for Water Quality}

Suva is the capital and a major port of Fiji Island in the center of the country surrounded by the Pacific Ocean. The city has a population of 263,670 within its $790.5 \mathrm{sqmi}(2048 \mathrm{sq} . \mathrm{km})$ area [13]. The majority of the population live around the coastal area and depend on ocean and coastal resources for their livelihoods. The tourism sector, which is an economic driver of the country, is dependent on good coastal water quality to support healthy corals and marine biodiversity. Sigatoka as a coastal town and a hub for tourism activities is the other location in this case study, which is located $125 \mathrm{~km}$ west from Suva. The Water Authority Fiji (WAF) manage and regulate the water supply, utilizing ground water and surface sources like river as sources for their water services nationwide. Figure 2 shows the geographical location of Fiji. Temperature exerts a major influence on biological activity and growth in our atmosphere. It is also a vital parameter because of its effect on water chemistry, as shown in Figure 3. The solubility of minerals usually escalates at a higher temperature. Water with higher temperatures can dissolve more minerals and will therefore have a higher concentration of inorganic ions or Total Dissolved Substances (TDS), resulting in higher conductivity. Warm water holds less dissolved oxygen (DO) than cold water and may not contain enough DO for the survival of diverse species of marine life. Water temperature must be measured every time water is sampled and investigated, no matter where it is being studied [14]. 


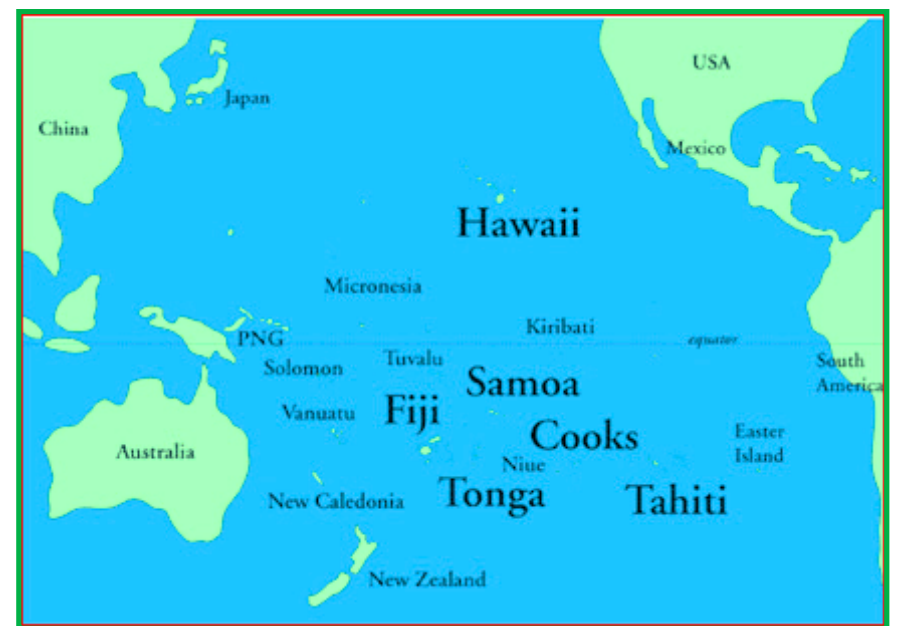

Figure 2. Position of the Fiji Islands in the Pacific Ocean [21].

Commonly used basic water quality monitoring parameters are temperature, $\mathrm{pH}$, conductivity, turbidity, and DO [15]. DO is the free oxygen in water necessary to sustain life. However, any increase in the microbial decomposition of organic matter in water bodies due to pollution leads to DO depletion. Oxidation-reduction potential (ORP) is measured in addition to DO as there are other chemical elements apart from oxygen that affect the oxidative capacity of rivers and lakes and provide additional information on the water quality and the degree of pollution. ORP is a measure of reducing or oxidizing potential that governs the biochemical processes in water and is an important monitoring parameter in drinking water and waste water processes and applications. ORP measurements are an indication of some oxidation- reduction reactions such as the corrosion of distribution pipes in drinking water systems, precipitation of iron and manganese compounds, nitrification and denitrification reactions, and microbial disinfection. ORP measurements are becoming a widespread parameter to monitor disinfection through chlorination in drinking water, and show that ORP is affected by $\mathrm{pH}$ as well [16]. There is a strong positive correlation between DO and ORP, and higher values create an optimum environment for nitrogen removal and enhanced microbial activity to break down organic matter [17]. It is apparent that for water quality monitoring, DO, ORP, and $\mathrm{pH}$ should be measured in conjunction. DO measures "residual oxygen" which is instantaneously available at a short period of time. However, ORP measures a kind of cumulative longer-term potential value. So for a continuous measurement, ORP is a much more reliable parameter to avoid any mislaid interpretation from the long-term measurement value of $\mathrm{DO}$. To categorize the water quality $\mathrm{pH}$, conductivity and ORP have been considered as important parameters in this research and were selected as KPIs for the comparison. Afterwards, a quality level is established to determine whether the water sample is polluted or non-polluted with the specific KPI range for the tested water samples. DO could be included in the suite of measurements in future, as there are additional channels that could be utilized. However, for the current measurements, the sites chosen such as Sigatoka, Rewa River, and Nabukalou Creek in Suva are all subjected to wastewater discharge, and perhaps ORP would be a better indicator for industrial and wastewater pollution. Figure 4 shows the schematic system architecture of the proposed SWQMS. FNDWQS [3,18], defined the $\mathrm{pH}$ ranges from 6.5 to 8.5 for drinking water with a temperature of $4{ }^{\circ} \mathrm{C}$. However, since the SWQMS system of this research works in real-time, therefore the temperature is used as a dynamic parameter which is directly co-related to the other KPIs. The first essential task was to identify the water parameters that can provide an indication of water contamination through an extensive review and research $[19,20]$; the parameters were selected to be composed of $\mathrm{pH}, \mathrm{ORP}$, conductivity, and temperature. 


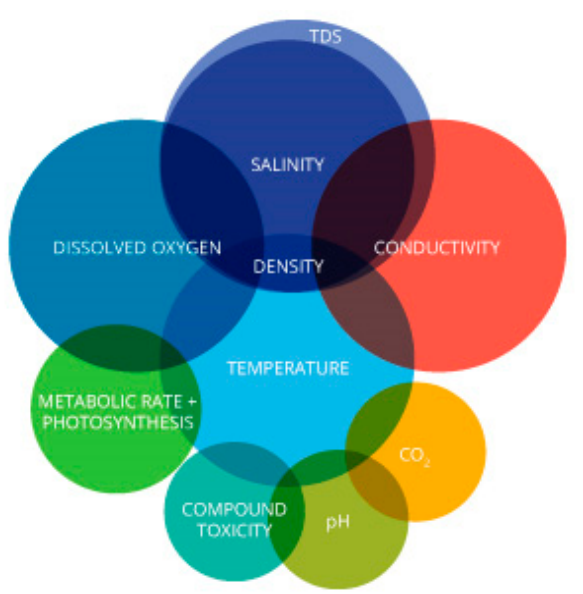

Figure 3. The temperature of water affects almost every other water parameter [22].

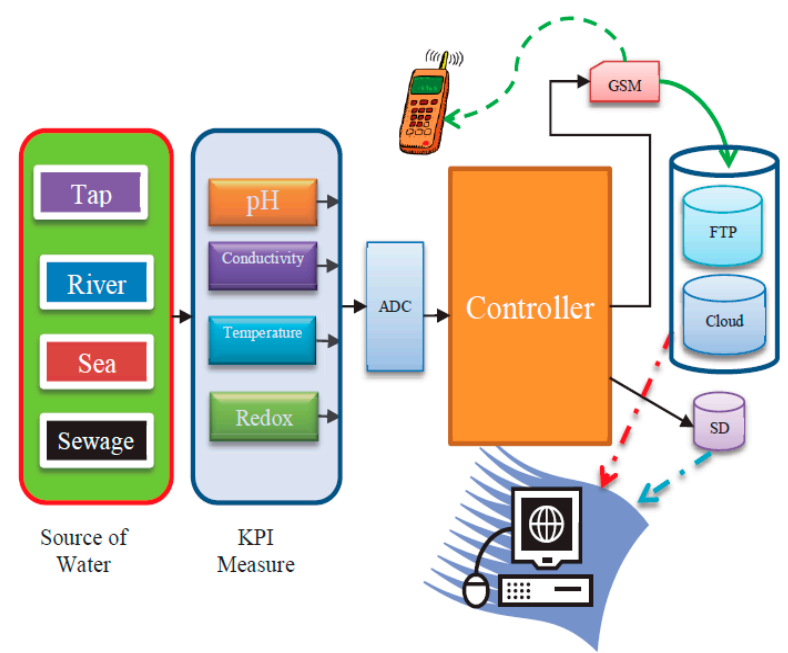

Figure 4. The system architecture of key performance indicator KPI measurements.

Table 1 provides a brief description of four KPIs chosen in this research and the accepted levels are obtained from a set of empirical results with various sources of surface water from Fiji during summer.

Table 1. KPIs for Water Quality.

\begin{tabular}{ccccccc}
\hline Parameter & Description & Node1 & Node2 & Node3 & Node4 & Node5 \\
\hline $\begin{array}{c}\text { Temperature } \\
\left({ }^{\circ} \mathrm{C}\right)\end{array}$ & $\begin{array}{c}\text { A critical component } \\
\text { that affects DO }\end{array}$ & $20-30$ & $20-30$ & $20-30$ & $20-30$ & $20-30$ \\
\hline Creek) & $\begin{array}{c}\text { (Rewa } \\
\text { River) }\end{array}$ & $\begin{array}{c}\text { (Sigatoka } \\
\text { Coast) }\end{array}$ & $\begin{array}{c}\text { (Tap } \\
\text { Water) }\end{array}$ & $\begin{array}{c}\text { Jetty) } \\
\text { pH }\end{array}$ & $\begin{array}{c}\text { Potential of hydrogen in } \\
\text { a solution }\end{array}$ \\
& Used to estimate acidity & $7.7-7.9$ & $4.5-10$ & $7.7-8.2$ & $7.7-8.1$ & $7.7-8.5$ \\
\hline $\begin{array}{c}\text { ORP } \\
(\mathrm{mV})\end{array}$ & $\begin{array}{c}\text { Used for the reduction } \\
\text { of the oxidation } \\
\text { potential of water }\end{array}$ & $0-(-2)$ & $190-220$ & $100-150$ & $300-600$ & $150-250$ \\
\hline $\begin{array}{c}\text { Conductivity } \\
(\mathrm{mS} / \mathrm{cm})\end{array}$ & $\begin{array}{c}\text { Used to identify ionic } \\
\text { strength and Total } \\
\text { Dissolved Salts (TDS) }\end{array}$ & $42-45$ & $70-80$ & $50-60$ & $55-70$ & $50-60$ \\
\hline
\end{tabular}




\section{System Design}

The system was comprised of a Waspmote V1.2 microcontroller board [23], water sensors, a SIM-900 GPRS/GSM module, and a GIS for interface and monitoring. The overall system is represented by Figure 5, while Figure 6 presents the GIS Node location for KPI measurement around the Fiji Islands. The SWQMS also has an analog to digital converter (ADC), a data storage card, and a GSM module.

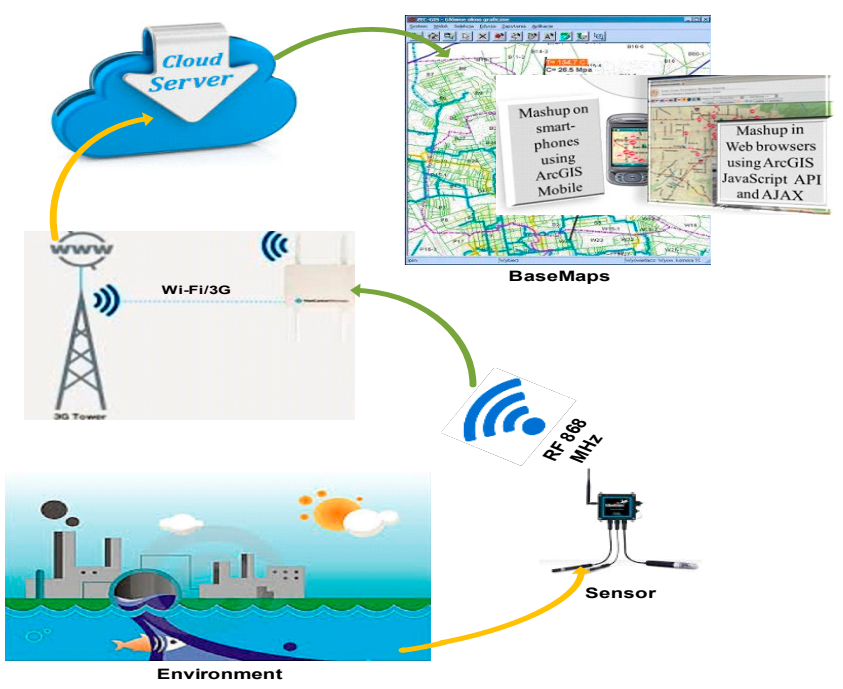

Figure 5. Schematic diagram of the system network.

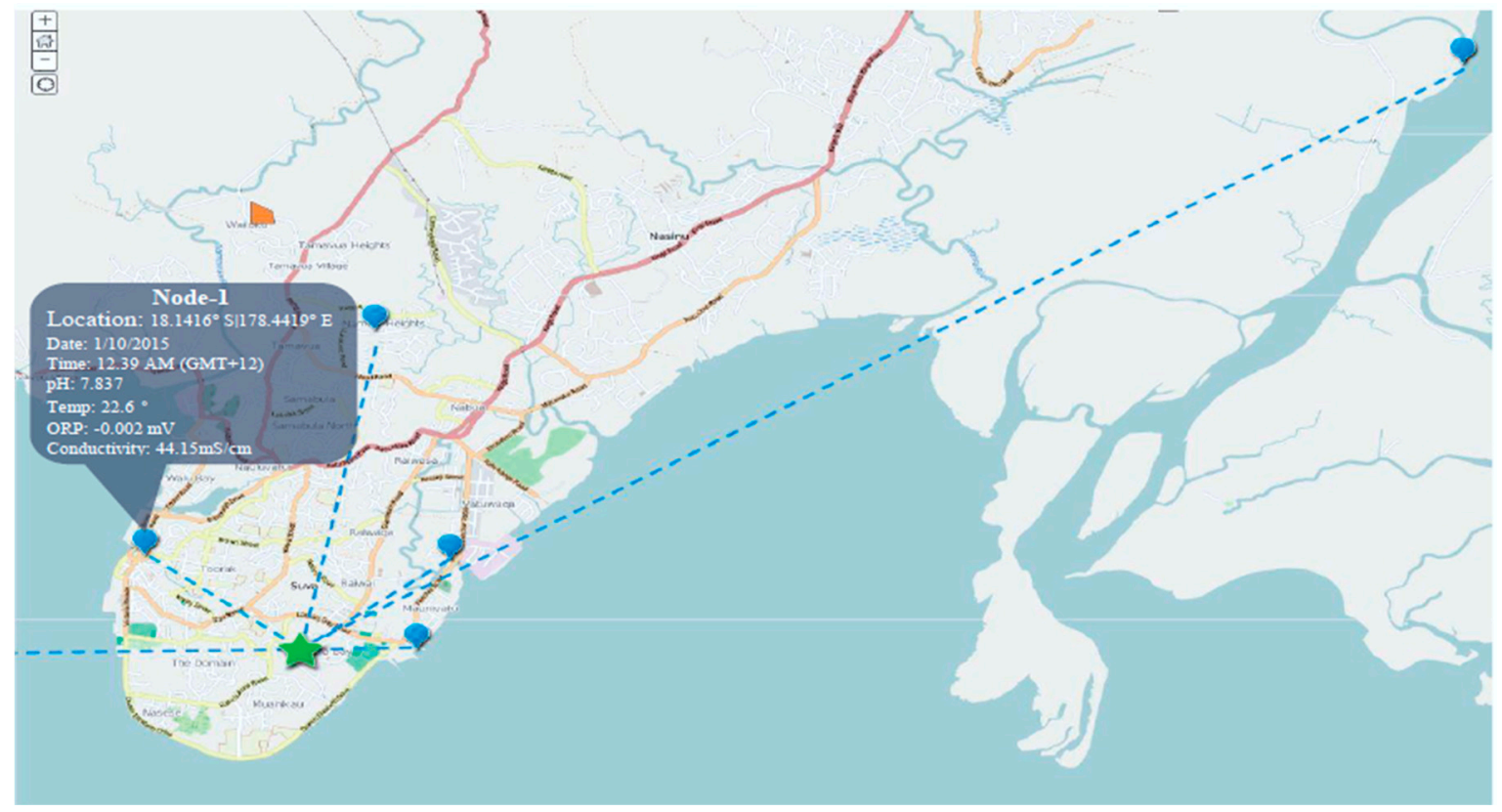

Figure 6. Designed GIS Map.

Furthermore, as the setup needs to work for a long time, power preservation is essential. To conserve the power, this system used a sleep mode operation around reading intervals of $1 \mathrm{~h}$. To extend battery life, a rechargeable Lithium-ion battery was used and the power supply was provided by a Photovoltaic (PV) system, as shown in Figure 7, while the specifications of the PV system are given in Table 2. To design a stand for SWQMS, a PV array with two strings characterized by a rated current of $2 \mathrm{~A}$ was used. Each string was subdivided into 11 modules characterized by a rated voltage of $1.2 \mathrm{~V}$ and connected in series. Thus, the total output voltage of the PV array was $13.2 \mathrm{~V}$, and its 
output had a current of $2 \mathrm{~A}$. The value of the DC-link capacitor was $25 \mu \mathrm{F}$, the line resistance $0.001 \Omega$ and inductance was $0.2 \mu \mathrm{H}$. The power supply system was simulated and designed under atmospheric conditions, for which the values of solar irradiation and temperature needed to be $1 \mathrm{kWm}^{-2}$ and $298 \mathrm{~K}$, respectively, to charge a lithium-ion battery of $12 \mathrm{~V}$. The PV system was integrated from the concept of previous research done by references $[24,25]$.

Table 2. Specification of the PV system used in SWQMS.

Cells in series: 10, parallel: 1

Modules in series: 2

Short circuit generator: $2 \mathrm{~A}$

Open circuit voltage: $12 \mathrm{~V}$

Filter and grid impedance: $\mathrm{R}=0.0282 \Omega, \mathrm{L}=0.0003 \mathrm{H}$

Boost converter: $\mathrm{RPV}=0.01 \Omega, \mathrm{LPV}=0.2 \mu \mathrm{H}, \mathrm{CPV}=0.5 \times 10^{-4} \mathrm{~F}$

DC link capacitance: $\mathrm{Cdc}=25 \mu \mathrm{F}$

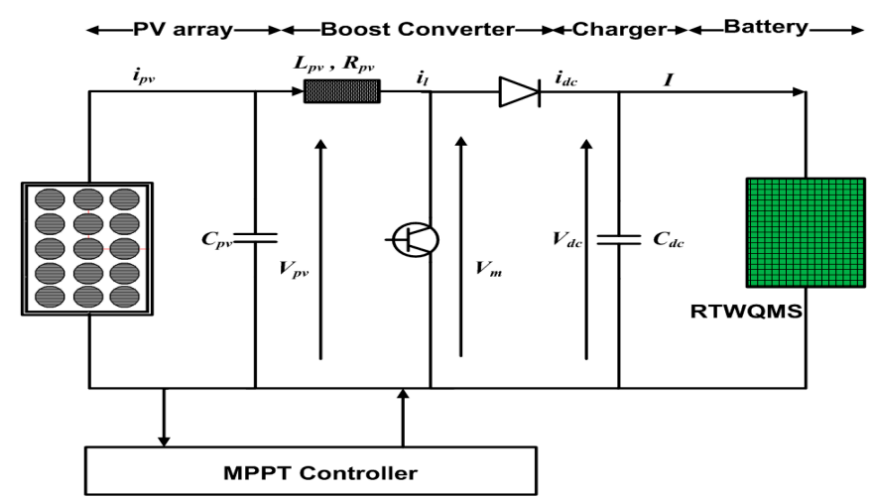

Figure 7. System for the power supply to the SWQMS.

The Waspmote architecture is based on the Atmega 1281, an eight (8) bit microcontroller for the SWQMS. The boot loader binary was executed by this microcontroller, which is stored in the FLASH memory. This enables the main program created by the user to be run. There are seven (7) analog inputs for the sensors which are connected to the microcontroller. Within the microcontroller lies a 10 bit successive approximation ADC. Furthermore, there are several digital pins which can be configured to act as either inputs or outputs when $0 \mathrm{~V}$ is low and $3.3 \mathrm{~V}$ is high. Figure 8 highlights the microcontroller, sensory sockets, and radio sockets along with other features.

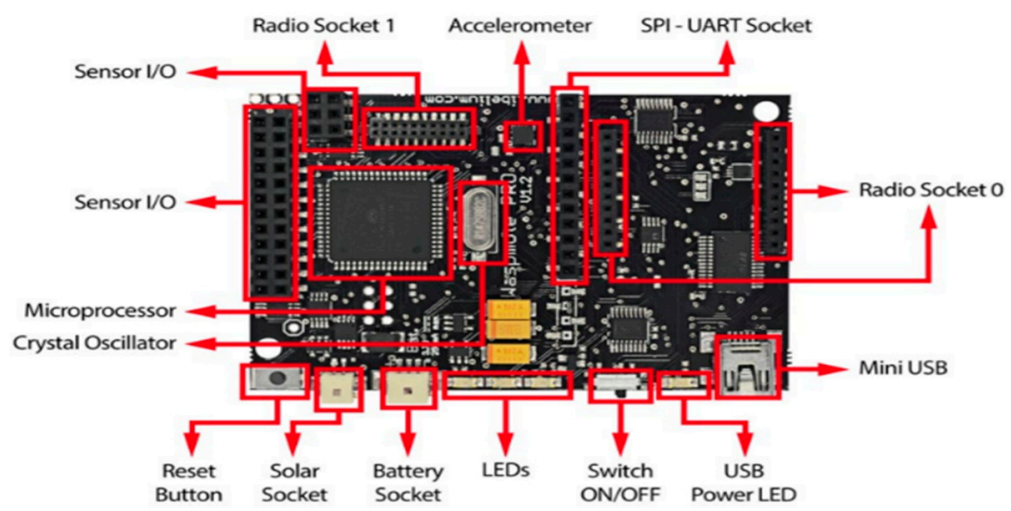

Figure 8. Waspmote Board Layout [23].

The GSM device uses a sim900 (provided by Simcon) as its baseband engine and as a communication module. It is a quad-band engine working with GSM 850 MHz, EGSM $900 \mathrm{MHz}$, DCS $1800 \mathrm{MHz}$, 
and PCS $1900 \mathrm{MHz}$. Furthermore, it has very small constructions where the dimensions are $24 \mathrm{~mm} \times$ $24 \mathrm{~mm} \times 3 \mathrm{~mm}$ to keep the design compact. The sim 900 is integrated with TCP/IP protocols, which is one of the most flexible forms of data transmission. Figure 9 presents a block diagram of Sim 900 showing the primary functions which are the radio frequency, baseband engine, and the flash memory along with other interfaces. Four (04) different types of sensors have been utilized for this SWQMS to measure the water quality in this case study, which is detailed later in this section, and the SWQMS setup is shown in Figure 10.

The Waspmote architecture is based on the Atmega 1281, an eight (8) bit microcontroller for the SWQMS. The boot loader binary is executed by this microcontroller, which is stored in the FLASH memory. This enables the main program created by the user to be run. There are seven (7) analog inputs for the sensors which are connected to the microcontroller. Within the microcontroller lies a 10-bit successive approximation ADC. Furthermore, there are several digital pins which can be configured to act as either inputs or outputs when $0 \mathrm{~V}$ is low and $3.3 \mathrm{~V}$ is high. Figure 8 highlights the microcontroller, sensory sockets, and radio sockets along with other features.

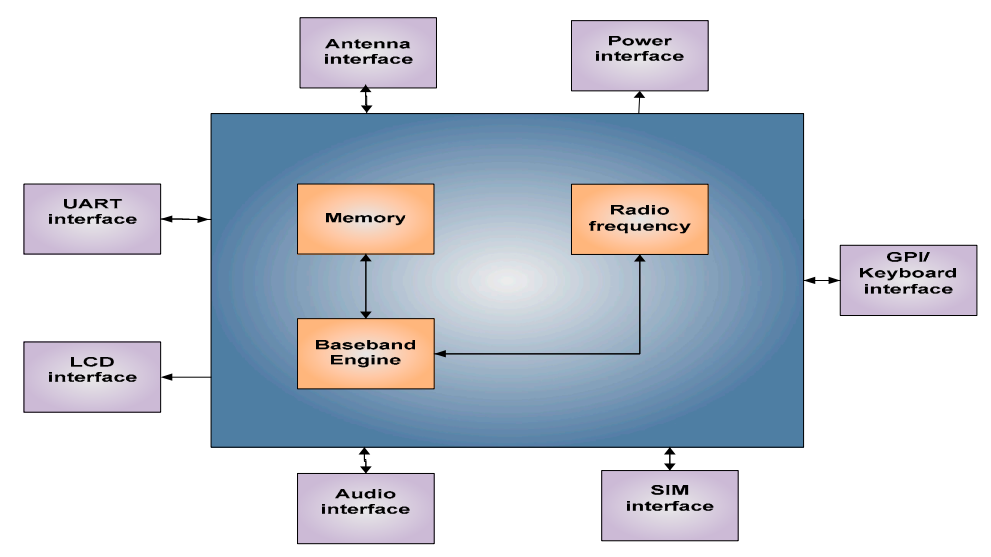

Figure 9. Sim900 Block Diagram.

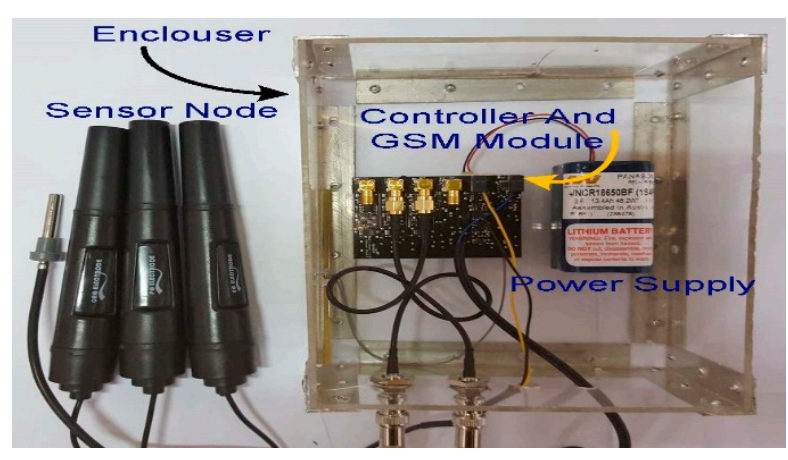

Figure 10. SWQMS with the sensors.

\subsection{Temperature Sensor}

The SWQMS uses a PT1000 sensor for its temperature measurements. The PT1000 sensor generally has a linear relationship over a small temperature range. In this research, the temperature range for sensing is $0-100^{\circ} \mathrm{C}$, which will provide a linear relationship between temperature and resistance as shown below in Equation (1).

$$
R_{t}=R_{0}\left(1+A_{t}+B_{t}^{2}\right)
$$

where $\mathrm{A}=3.9083 \times 10^{-3}{ }^{\circ} \mathrm{C}, \mathrm{B}=-5.775 \times 10^{-7}{ }^{\circ} \mathrm{C}$, and $R_{0}$ is the temperature at $0{ }^{\circ} \mathrm{C}$. 
The temperature sensor is used in a voltage divider configuration with a $1 \mathrm{~K} \mathrm{ohm}$ resistor, hence $V_{t}$ can be obtained using Equation (2) as follows:

$$
V_{t}=V_{r e f}\left(\frac{R_{t}}{R_{t}+R_{0}}\right)
$$

This is then amplified by an instrumental amplifier with a gain of 11 and fed to a 24 bit ADC. Figure 11 below shows a summarized model of the temperature sensors.

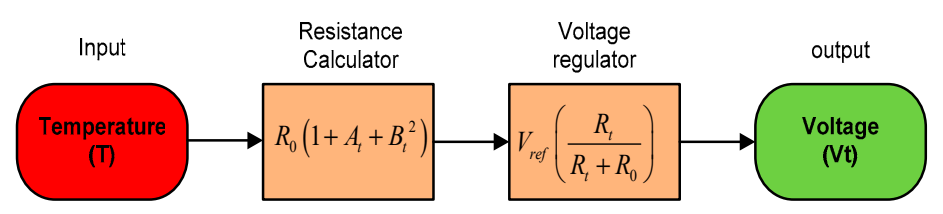

Figure 11. The sensor mathematical model.

\subsection{Conductivity Sensor}

The SWQMS also uses a conductivity sensor. The sensor has two (2) electrode types, which were constructed using platinum. This sensor determines the conductivity of a solution by applying a small AC current through the solution. An AC signal is used to avoid polarization of the platinum electrodes.

Conductivity can be calculated using ohms law, shown here as Equation (3). Since the supply to the electrodes is an AC current, the voltage can be measured between the two electrodes and hence the resistance of the solution can be found.

$$
V=I R
$$

where $R$ is the resistance of the solution. Conductance $(G)$ can also be found using the Equation (4).

$$
G=\frac{I}{R}
$$

Finally, the conductivity of the solution can be calculated using the cell constant obtained from the calibration process. This constant is specified in the manufacturer's datasheet [21]; but it is advised to carry out the calibration using a solution of known resistivity using Equation (5).

$$
k=G \cdot K
$$

where $k=$ conductivity $(\mathrm{S} / \mathrm{cm}), G=$ conductance $(S)$, and where $G=1 / R$ and $K=\operatorname{cell}$ constant $\left(\mathrm{cm}^{-1}\right)$. A summarized model of the conductivity sensor is described below in Figure 12.

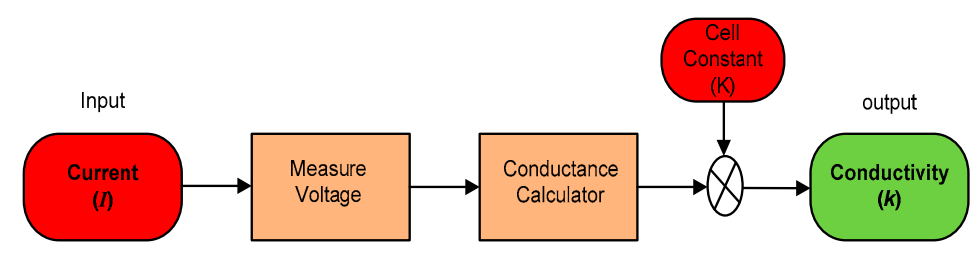

Figure 12. Model of a conductivity sensor.

\subsection{PH Sensor}

This research exercises the use of a combination electrode to measure the $\mathrm{pH}$ of a solution. Since the design and operation of the $\mathrm{pH}$ sensor used in the SWQMS are very complex, it is necessary to understand the potential between the two (2) electrodes and how it is interpreted. The $\mathrm{pH}$ value can be obtained by the negative logarithm of the $\mathrm{H}+$ in a given solution $(\mathrm{pH}=\log \mathrm{aH}+$ ). This value of 
$\mathrm{pH}$ needs to be converted into a voltage signal using the following the Equation (6) to obtain the sensor's output.

$$
E_{p h}=E_{0}+k_{n f} \cdot T\left(\log \mathrm{a}_{\mathrm{H}+}\right)
$$

where Nernst factor is $k_{n f}=2.3026 x \frac{R T}{F}, E=$ measured potential $(\mathrm{mV}), T=$ Temperature in $K$, and $F=$ the Faraday constant $\left(96,485 \mathrm{C} \mathrm{mol}^{-1}\right)$;

As the voltage produced by the electrodes has a linear relationship to the $\mathrm{pH}$ of the solution, at the reference $\mathrm{pH}$ of 7, the potential between the electrodes is $0 \mathrm{~V}$. At an acidic or low $\mathrm{pH}$ level, the potential between the electrodes is linear. Likewise, at a high $\mathrm{pH}$, the potential between the electrodes will be at the opposite polarity. The overall working principle of the $\mathrm{pH}$ sensor can be seen in the following mathematical model shown in Figure 13.

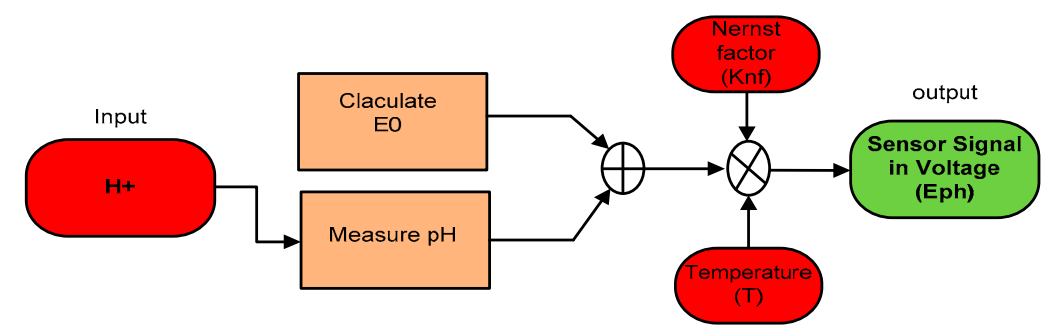

Figure 13. Sensor mathematical model.

\subsection{ORP Sensor}

The oxidation Reduction Potential (ORP) sensor is the other types of sensor that used for SWQMS in a similar manner to that of the $\mathrm{pH}$ sensor. The sensor consists of two electrodes, a reference electrode and an ORP electrode. It uses inert metals (platinum in this case) which give up or accept electrons for an oxidant/reductant. This is done until a potential outcome is developed that is linear to the ORP of the solution. There is no unit conversions done since the potential is already in mili volt $(\mathrm{mV})$. The electrode behavior is defined by the Nernst equation shown in Equation (7):

$$
E=E_{0}-\frac{R T}{n F} \ln \frac{C_{o x}}{C_{r e d}}
$$

where $E_{0}=$ measured potential $(\mathrm{mV})$ at a concentration of $C_{o x}=C_{\text {red }} ; R=$ universal gas constant; $n=$ electrical charge of the ion, $C_{o x}=$ oxidant concentration in moles $/ \mathrm{L}$, and $C_{r e d}=$ reductant density in moles/L.

\section{GIS Design for the SWQMS}

The objective of this case study is to provide a reliable water quality monitoring system. It is essential that the system should work in real-time and be environmentally friendly. SWQMS has been developed to improve the entire performance of the water management system and to ensure there is a sustainable environment for cities and societies.

GeoMedia software is used as part of the GIS integration in SWQMS to visualize and analyze KPI measurement data. One of the important capabilities of GIS is a working capability with both digital spatial features [26] and the related information for map [27,28]. KPIs from several nodes are logged with their coordinates and Microsoft Access database has been used and linked with node data. Dynamic quantities are updated utilizing GeoMedia Workspace. Queries can be performed within the Workspace to filter the spatial and non-graphical attributes. PICs has been separated into various area/zones to recognize the exact site utilizing GIS, as shown in Table 3.

The quick bird satellite imagery at $0.6 \mathrm{~m}$ resolution is being utilized to generate the base map. Intergraph's Geo-Media and Global Positioning System (GPS) 7.2, have been used to design a GIS 
interface. Suva areas were arranged by using the GSM located in several predefined sites: the Base Map, Area Map, and Digital Elevation Model.

Table 3. Zones in GIS.

\begin{tabular}{cc}
\hline Node on the Zone & Point within a Zone Related to Water Resource \\
\hline Interconnection & Sea Current \\
Regional & Highest region in PICs \\
Extra Regional & Region external of Fiji \\
Sub Regional & Wide area/zone below regional area/zones of Fiji \\
Local & Secondary level above cell (i.e., Suva) \\
Unit Cell & Fundamental level under local area/zone \\
\hline
\end{tabular}

\section{Result and Discussion}

The experimental setup has been established in different location of the Fiji Islands (i.e., Suva City and the Sigatoka Coastal area; as shown in Figure 6) using five nodes and a GIS interface to study the water quality parameters. Different sources and locations were used to conduct the research (i.e., Marine, Coastal, River, Creek and Tap) for aforementioned KPIs (i.e., Temp., pH, Conductivity, and ORP; as shown earlier in Table 1). The measurements were taken within 1 foot of water depth from the surface. Geographic information system within the experimental setup allows the user to access the data necessary from any location through the internet. However, this section will discuss the statistical analysis of the data collected during the experiment to measure the reliability/efficiency of the proposed SWQMS.

KPIs data from all the nodes were analyzed, which demonstrates the fundamental co-relation between KPIs, for instance, temperature has a linear positive co-relationship to oxidation-reduction and also with the conductivity, but a linear negative co-relationship to $\mathrm{pH}$. The results also showed consistency with a slight deviation, which was found to be the impact of peripheral variables (i.e., high/low tide).

Table 4 presents the Mean and Standard Deviation (SD) of the four parameters/KPIs measured for a different type of waters. It has been observed that the average temperature measured during the investigation period varies from a minimum of $25.39^{\circ} \mathrm{C}$ found in creeks to a maximum of $26.22{ }^{\circ} \mathrm{C}$ found in rivers. An analysis of variance test was used and found that the variation of the temperature in different water is significant $(p<0.001)$. The difference range observed in temperature is very minimal or can be explained by any other KPIs. Temperature can be defined as a quantity of the average thermal energy of an element [29]. This energy can be shifted between elements as the movement of heat. Heat transfer, whether, from light, another water source, or pollution such as hot water discharge can change the water's temperature [22]. The Nabukalou creek is a one of the most polluted waterbodies in the city and a low temperature rules out any thermal pollution. Its low temperature could be attributed to large buildings alongside the creek providing some shade from direct sunlight, whereas other sites are exposed to direct sunlight.

Table 4. Mean and SD of the four parameters/KPIs in different types of waters.

\begin{tabular}{cllll}
\hline \multirow{2}{*}{ Type of Water } & \multicolumn{4}{c}{ Mean (SD) } \\
\cline { 2 - 5 } & Temp & Conductivity & pH & ORP \\
\hline Marine & $26.186(0.72)$ & $51.477(0.50)$ & $7.925(0.10)$ & $124.907(9.23)$ \\
Creek & $25.39(0.72)$ & $44.207(0.50)$ & $7.834(0.07)$ & $-0.726(0.57)$ \\
Coastal & $25.887(0.72)$ & $51.178(0.50)$ & $8.54(0.10)$ & $245.116(9.75)$ \\
River & $26.224(0.72)$ & $70.218(0.50)$ & $7.387(0.10)$ & $198.398(9.33)$ \\
Tap & $25.797(0.72)$ & $59.073(0.50)$ & $7.923(0.10)$ & $321.481(9.75)$ \\
\hline F $(p$-value) & $5.1445^{* * *}(0.001)$ & $9059.1^{* * *}(<0.001)$ & $394.57^{* * *}(<0.001)$ & $13445^{* * *}(<0.001)$ \\
\hline \multicolumn{5}{c}{$* * *$ Significant at $0.1 \%$ (Very strong Co-relation). }
\end{tabular}


Standard deviation for temperature and conductivity for all sources were varied on three decimal point and rounding off gives the same values as those shown in Table 4.

$\mathrm{pH}$ was found to be different in different sources of water $(p<0.001)$. The maximum $\mathrm{pH}$ was found in marine water (Mean $=8.54, \mathrm{SD}=0.10$ ) and the minimum was obtained in river water (Mean $=7.39, \mathrm{SD}=0.10)$. The $\mathrm{pH}$ value of marine water responds to the following changes: dissolved $\mathrm{CO}_{2}$ concentrations, alkalinity, hydrogen ion concentrations, as well as slightly due to temperature changes. The $\mathrm{pH}$ values obtained for different water sources were within the typical range, particularly for seawater where the modeled $\mathrm{pH}$ values were 8.08-8.33 [30]. The $\mathrm{pH}$ of the river was comparable to the $\mathrm{pH}$ of 7.22 obtained for Chao Phraya River, Bangkok, Thailand, which is more polluted than Rewa River. The intrusion of saltwater into Nabukalou Creek could slightly elevate the $\mathrm{pH}$. However, the $\mathrm{pH}$ of a water system is greatly affected by the natural buffer or alkalinity of the water body, and alkalinity was not measured in this project to account for differences in $\mathrm{pH}$ for different water sources.

Variation in conductivity was found to be statistically different $(p<0.001)$ with the minimum found in the creek (Mean $=44.21, \mathrm{SD}=0.50$ ) and the maximum found in the river (Mean $=70.22, \mathrm{SD}=0.50$ ). Surprisingly, the conductivity of the Nabukalou Creek is low despite the fact that the creek has poor water quality status with large inter-annual variability in the parameters monitored [31]. Despite sewage and industrial effluent being discharged into the creek, it still shows that ion concentrations are diluted with a large amount of rainfall decreasing the TDS, hence decreasing the conductivity. There have been studies that approximate TDS from conductivity measurements, but the relationship is not always linear and is affected by salinity levels [32]. However, for the natural creek waters, it should be relatively simple to approximate TDS from conductivity [32]. Sea water normally records higher conductivity than freshwater. In contrast, the Rewa river recorded the highest conductivity. The plausible explanation for this observation could be that there is some mixing of freshwater with salt water, and this could have been confirmed by salinity measurements. The other reasons could be that Rewa River runs through the agricultural plains and therefore experiences agricultural run-off, dissolution of ions from nearby rocks, and wastewater discharge and waste disposal into the river.

Variation in ORP is found with the minimum in the creek (Mean $=-0.73, \mathrm{SD}=0.07$ ) and the maximum in tap water (Mean $=321.48, \mathrm{SD}=9.75$ ). The ORP level will govern which reactions are prevalent along with the $\mathrm{DO}$ and $\mathrm{pH}$ levels. Research data reveals that mineral waters, including tap water, have an ORP of $+200 \mathrm{MV}$ to $+400 \mathrm{MV}$ [33]. The tested tap water falls within this range and suggest that it is an oxidizing condition and that there is lots of oxygen present, probably due to the small amount of organic matter and even smaller amount of microbial activity due to effective chlorination disinfectant processes. The ORP is on the lower side at the marine site, probably due to the presence of high organic matter, resulting in decomposition and therefore reducing the DO. An interesting feature of ORP measurements is the negative values observed at the Nabukalou creek suggesting a reduced environmental quality due to pollution. This confirms the findings of other studies that found high levels of fecal coliforms and nutrients from human discharge and industrial wastewater in the creek. Obtaining a negative value for Nabukalou creek increases the confidence of the data obtained from SWQMS. The data measured for polluted water provides an ORP of around $-2 \mathrm{mV}$ and conductivity within a $42-45 \mathrm{mS} / \mathrm{cm}$ range, which indicates that the sample water is polluted. It was expected as the water sample was collected from Node-1 (Nabukalou Creek having waste lines (Sewage) connected to the creek). A summary is given in Table 4 for all other nodes used in this case study.

A different set (Node-3; Sigatoka coastal water) of data for all KPIs were analyzed and presented in this section to validate the system reliability and sensitivity. The experiment was conducted over the course of a month. The starting date of the experiment was 7 December 2015 and the experiment were concluded on 6 January 2016. The following graphs in Figure 14 shows the average hourly (from hours 1-24) variations of the values of four KPIs/parameters during the investigation period within an interval of 5 min every hour in a particular day and only average hour readings from one (1) day are shown here as a reference in Table 5. 
Table 5. Hourly Average KPI Data for a Day (6 pm 7 January 2015 to 5 pm 8 January 2015) at Node-3; Sigatoka coastal.

\begin{tabular}{cccc}
\hline Temperature $\left({ }^{\circ} \mathbf{C}\right)$ & Conductivity $(\mathbf{m S} / \mathbf{c m})$ & $\mathbf{p H}$ & ORP $(\mathbf{m V})$ \\
\hline 26.691 & 51.953 & 8.357 & 237.796 \\
26.627 & 51.735 & 8.467 & 252.166 \\
26.541 & 51.560 & 8.486 & 242.552 \\
26.285 & 51.440 & 8.488 & 241.261 \\
25.992 & 51.081 & 8.606 & 243.697 \\
25.832 & 50.984 & 8.587 & 232.985 \\
25.465 & 50.994 & 8.608 & 237.179 \\
25.181 & 51.037 & 8.647 & 240.597 \\
24.393 & 50.810 & 8.639 & 239.190 \\
24.313 & 50.323 & 8.655 & 238.332 \\
24.724 & 50.833 & 8.678 & 234.635 \\
25.544 & 51.075 & 8.715 & 235.030 \\
26.705 & 51.591 & 8.545 & 236.765 \\
26.102 & 51.247 & 8.582 & 238.198 \\
25.765 & 50.875 & 8.525 & 242.954 \\
26.154 & 51.709 & 8.491 & 248.849 \\
26.744 & 51.971 & 8.358 & 245.905 \\
26.632 & 51.971 & 8.463 & 240.880 \\
26.538 & 51.587 & 8.469 & 252.111 \\
26.290 & 51.489 & 8.515 & 254.118 \\
26.010 & 50.571 & 8.579 & 256.151 \\
25.857 & 50.588 & 8.597 & 257.566 \\
25.690 & 50.588 & 8.558 & 263.407 \\
25.201 & 50.399 & 8.348 & 270.449 \\
\hline
\end{tabular}

The data highlighted that there were little variations in $\mathrm{pH}$, conductivity, and ORP readings over the $24 \mathrm{~h}$ period and therefore it could be concluded that the sensors were reliable. Conductivity values were observed in the range of 50.3-51.95, $\mathrm{pH}$ values had the range 8.4-8.7, and ORP was observed in the range of $232-252 \mathrm{mV}$. These all show signs of healthy water according to research gathered [3,18-20]. Figure 15 and Table 6 show the temperature relationship with $\mathrm{pH}$, conductivity, and ORP for a particular day, which confirms the trends that they follow a linear positive or negative co-relation inclined with the theories. More specifically, conductivity is strongly positively correlated with temperature in all types (04) of water. $\mathrm{pH}$ is strongly negatively correlated with temperature in all types (03) of water, except in creek water. ORP has no significant correlation with temperature except for the creek water in this case study.

Predictions of conductivity (y1), $\mathrm{pH}(\mathrm{y} 2)$ and ORP (y3) for a given temperature have also been modeled that can be used in further applications. However, for predicting the conductivity, $\mathrm{pH}$, and ORP, the following Table 7 presents the best model found using the regression analysis. Table 7 also presents the predicted values of conductivity, $\mathrm{pH}$, and ORP when the temperature of the day was observed at $25^{\circ} \mathrm{C}$. 

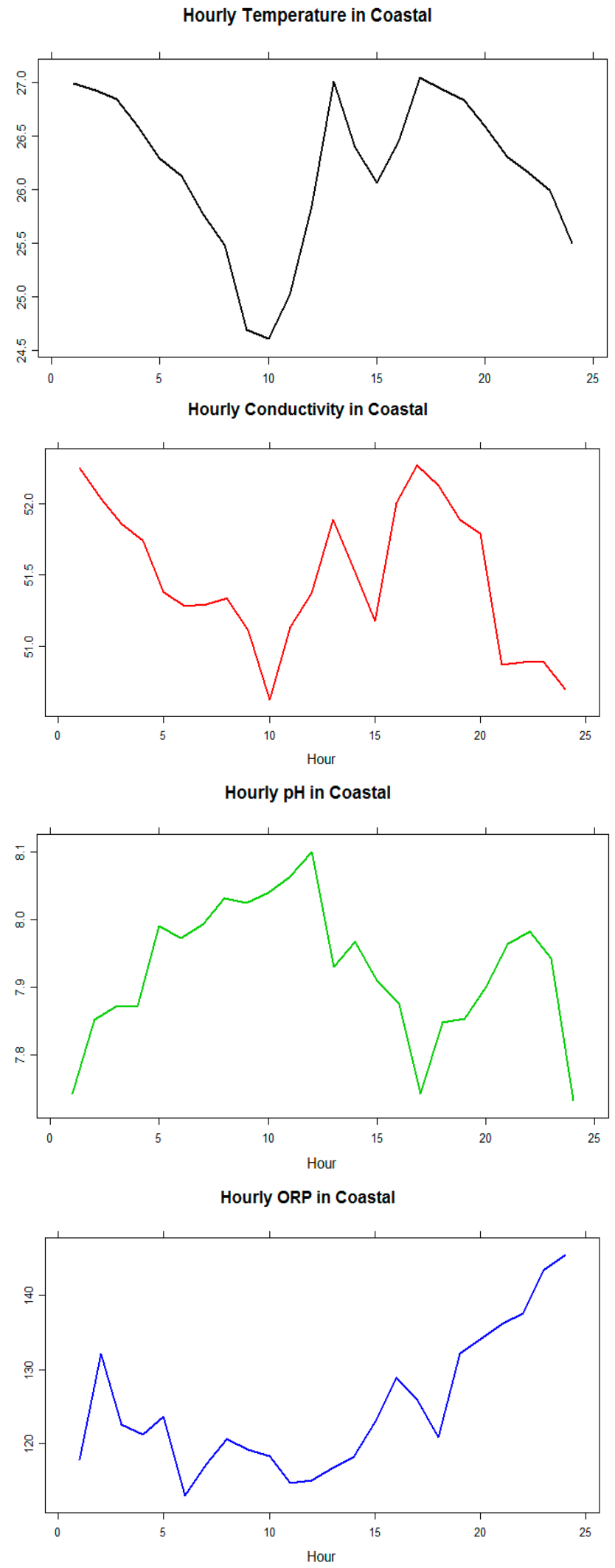

Figure 14. Values of the KPIs/parameters in Sigatoka coastal water. 

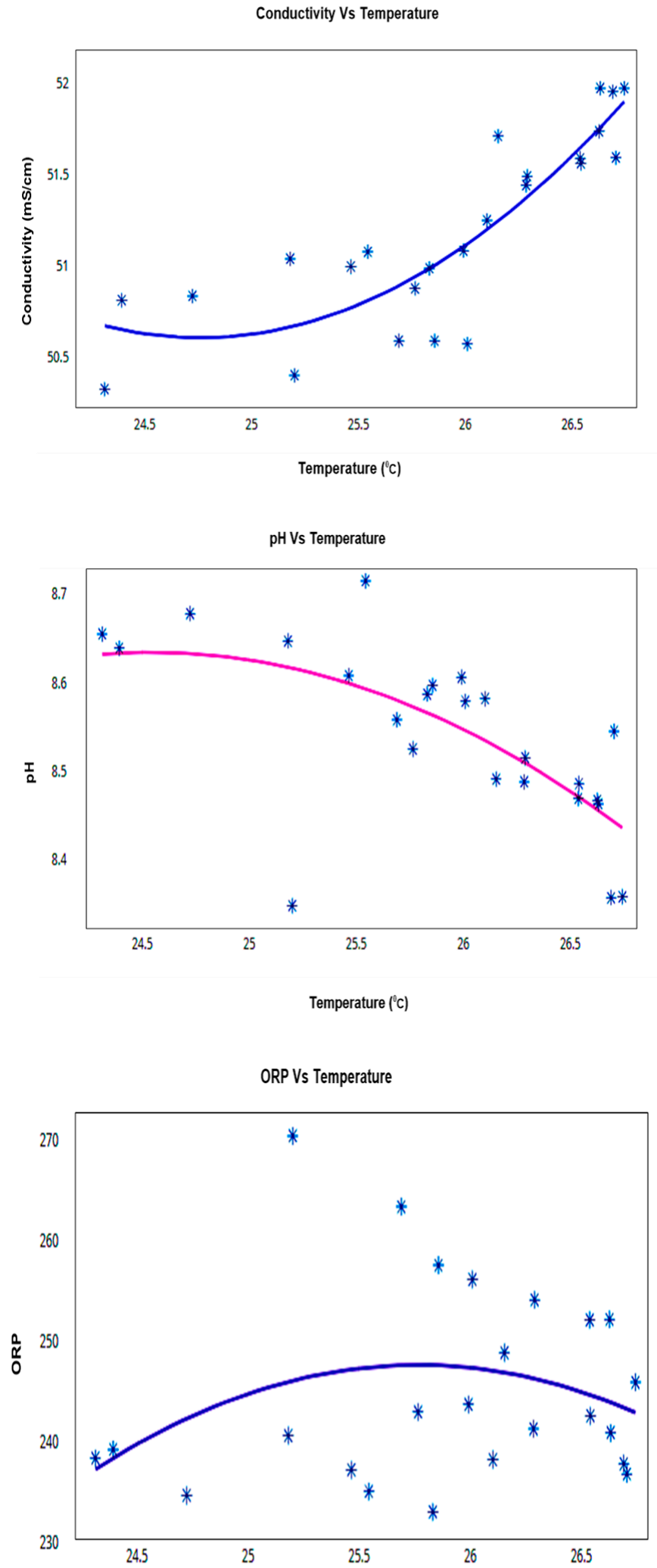

Temperature ("c)

Figure 15. Co-Relation Graphs for Node-3 (Sigatoka coastal water) for daily measurement. 
Table 6. KPI Co-Relations for daily measurement.

\begin{tabular}{cccc}
\hline \multirow{2}{*}{ Type of Water } & \multicolumn{3}{c}{ Temperature Versus } \\
\cline { 2 - 4 } & Conductivity $\boldsymbol{r}(\boldsymbol{p}$-Value) & $\mathrm{pH} \boldsymbol{r}(\boldsymbol{p}$-Value) & ORP $\boldsymbol{r}(\boldsymbol{p}$-Value) \\
\hline Coastal & $0.80^{* * *}(<0.001)$ & $-0.63^{* * *}(0.001)$ & $0.13(0.532)$ \\
Creek & $0.80^{* * *}(<0.001)$ & $-0.22(0.307)$ & $0.53^{* *}(0.008)$ \\
Marine & $0.80^{* * *}(<0.001)$ & $-0.63^{* * *}(0.001)$ & $0.11(0.623)$ \\
River & $0.80^{* * *}(<0.001)$ & $-0.63^{* * *}(0.001)$ & $0.13(0.550)$ \\
Tap & $0.80^{* * *}(<0.001)$ & $-0.64^{* * *}(0.001)$ & $0.11(0.623)$ \\
\hline
\end{tabular}

** Significant at $1 \%$ (Moderate co relation), ${ }^{* * *}$ Significant at $0.1 \%$ (Significant Co-relation).

Table 7. Prediction of conductivity (y1), $\mathrm{pH}(\mathrm{y} 2)$, and ORP (y3) for a given temperature $\left(25^{\circ} \mathrm{C}\right)$.

\begin{tabular}{|c|c|c|c|c|}
\hline Water Source & Predicted Variable & Model & $\begin{array}{c}\text { Regression Coefficient } \\
(p \text {-Value })\end{array}$ & $\begin{array}{c}\text { Predicted Value } \\
\text { at } x=25^{\circ} \mathrm{C}\end{array}$ \\
\hline \multirow{3}{*}{ Marine } & Conductivity $\left(y_{1}\right)$ & $\hat{y}_{1}=\hat{\beta}_{0}+\hat{\beta}_{1} x+\hat{\beta}_{2} x^{2}$ & $\begin{array}{l}\hat{\beta}_{0}=245.47^{* *}(0.001) \\
\hat{\beta}_{1}=-15.75^{* *}(0.001) \\
\hat{\beta}_{2}=0.3182^{* *}(0.001)\end{array}$ & 50.62 \\
\hline & $\mathrm{pH}\left(y_{2}\right)$ & $\hat{y}_{1}=\hat{\beta}_{0}+\hat{\beta}_{1} x$ & $\begin{array}{c}\hat{\beta}_{0}=10.818^{* * *}(<0.001) \\
\hat{\beta}_{1}=-0.088^{* *}(0.001)\end{array}$ & 8.62 \\
\hline & $\operatorname{ORP}\left(y_{3}\right)$ & No significant model & - & - \\
\hline \multirow{3}{*}{ Coastal } & Conductivity $\left(y_{1}\right)$ & $\hat{y}_{1}=\hat{\beta}_{0}+\hat{\beta}_{1} x+\hat{\beta}_{2} x^{2}$ & $\begin{array}{l}\hat{\beta}_{0}=250.511^{* *}(0.001) \\
\hat{\beta}_{1}=-15.94^{* *}(0.001) \\
\hat{\beta}_{2}=0.3182^{* *}(0.005)\end{array}$ & 50.91 \\
\hline & $\mathrm{pH}\left(y_{2}\right)$ & $\hat{y}_{1}=\hat{\beta}_{0}+\hat{\beta}_{1} x$ & $\begin{array}{c}\hat{\beta}_{0}=10.229 * * *(<0.001) \\
\hat{\beta}_{1}=-0.088^{* *}(0.001)\end{array}$ & 8.03 \\
\hline & $\operatorname{ORP}\left(y_{3}\right)$ & No significant model & - & - \\
\hline \multirow{3}{*}{ Creek } & Conductivity $\left(y_{1}\right)$ & $\hat{y}_{1}=\hat{\beta}_{0}+\hat{\beta}_{1} x+\hat{\beta}_{2} x^{2}$ & $\begin{array}{l}\hat{\beta}_{0}=230.76^{* *}(0.001) \\
\hat{\beta}_{1}=-15.43^{* *}(0.006) \\
\hat{\beta}_{2}=0.3182^{* *}(0.005)\end{array}$ & 43.81 \\
\hline & $\mathrm{pH}\left(y_{2}\right)$ & No significant model & - & - \\
\hline & $\operatorname{ORP}\left(y_{3}\right)$ & $\hat{y}_{1}=\hat{\beta}_{0}+\hat{\beta}_{1} x+\hat{\beta}_{2} x^{2}$ & $\begin{array}{l}\beta_{0}=-272.89^{* *}(0.022) \\
\hat{\beta}_{1}=-21.257^{* *}(0.025) \\
\hat{\beta}_{2}=0.3182^{* *}(0.005)\end{array}$ & -0.66 \\
\hline \multirow{3}{*}{ River } & Conductivity $\left(y_{1}\right)$ & $\hat{y}_{1}=\hat{\beta}_{0}+\hat{\beta}_{1} x+\hat{\beta}_{2} x^{2}$ & $\begin{array}{l}\hat{\beta}_{0}=269.86^{* *}(0.001) \\
\hat{\beta}_{1}=-15.96^{* *}(0.006) \\
\hat{\beta}_{2}=0.3182^{* *}(0.005)\end{array}$ & 69.65 \\
\hline & $\mathrm{pH}\left(y_{2}\right)$ & $\hat{y}_{1}=\hat{\beta}_{0}+\hat{\beta}_{1} x$ & $\begin{array}{l}\hat{\beta}_{0}=9.694^{* * *}(<0.001) \\
\hat{\beta}_{1}=-0.088^{* *}(0.001)\end{array}$ & 7.49 \\
\hline & $\operatorname{ORP}\left(y_{3}\right)$ & No significant model & - & - \\
\hline \multirow{3}{*}{ Tap } & Conductivity $\left(y_{1}\right)$ & $\hat{y}_{1}=\hat{\beta}_{0}+\hat{\beta}_{1} x+\hat{\beta}_{2} x^{2}$ & $\begin{array}{l}\hat{\beta}_{0}=251.95^{* *}(0.001) \\
\hat{\beta}_{1}=-15.69^{* *}(0.006) \\
\hat{\beta}_{2}=0.3182^{* *}(0.005)\end{array}$ & 58.54 \\
\hline & $\mathrm{pH}\left(y_{2}\right)$ & $\hat{y}_{1}=\hat{\beta}_{0}+\hat{\beta}_{1} x$ & $\begin{array}{l}\hat{\beta}_{0}=10.15^{* * *}(<0.001) \\
\hat{\beta}_{1}=-0.086^{* *}(0.001)\end{array}$ & 7.99 \\
\hline & $\operatorname{ORP}\left(y_{3}\right)$ & No significant model & - & - \\
\hline
\end{tabular}

Through the 30 days deployment, the results observed had fluctuations, however this was anticipated since tidal behavior was not expected to carry over from day-to-day. Furthermore, the KPI parameters behavior was mostly influenced by temperature. The 30 days results were measured with a daily average reading for a month at Node-3 (Sigatoka coastal water) and tabulated in Table 8. Table 9 presents the correlation between daily average KPIs data for all four (04) types of water. Conductivity values are strongly positively correlated with temperature for all types of water. It is observed that $\mathrm{pH}$ was strongly negatively correlated with temperature for all types of water. Although it was observed that the ORP parameter had no correlation with temperature for any types of water that are used in this case study, it is still recommended that one calibrates an ORP sensor before any critical measurements 
and uses multiple ORP sensors to cross-reference or conduct further research with other measurements such as sulfides or nitrates. As the values of correlations are the same for all three (03) types of water, except for the ORP in creeks, the results in Table 9 also presents these values with changes of temperature, the rate of change of conductivity, and $\mathrm{pH}$ in any types of water at the same ratio, while ORP does not follow this phenomenon.

Table 8. Daily Average KPI Data for a month at Node-3: Sigatoka coastal Water.

\begin{tabular}{|c|c|c|c|}
\hline \multicolumn{3}{|c|}{ Conductivity } & \multirow{2}{*}{$\begin{array}{c}\text { ORP } \\
(\mathrm{mV})\end{array}$} \\
\hline Temperature $\left({ }^{\circ} \mathrm{C}\right)$ & $(\mathrm{mS} / \mathrm{cm})$ & $\mathrm{pH}$ & \\
\hline 25.858 & 51.137 & 8.549 & 245.379 \\
\hline 25.671 & 51.212 & 8.555 & 246.202 \\
\hline 25.724 & 51.194 & 8.551 & 250.301 \\
\hline 26.068 & 51.604 & 8.518 & 225.550 \\
\hline 26.074 & 51.650 & 8.501 & 241.815 \\
\hline 25.808 & 51.135 & 8.571 & 236.159 \\
\hline 25.944 & 51.185 & 8.581 & 242.197 \\
\hline 26.726 & 51.603 & 8.481 & 243.232 \\
\hline 26.816 & 51.876 & 8.484 & 244.939 \\
\hline 27.029 & 52.100 & 8.398 & 241.819 \\
\hline 27.080 & 52.003 & 8.369 & 242.003 \\
\hline 26.735 & 51.709 & 8.408 & 244.487 \\
\hline 26.831 & 51.507 & 8.472 & 245.238 \\
\hline 26.507 & 51.588 & 8.493 & 239.976 \\
\hline 26.471 & 51.770 & 8.491 & 217.259 \\
\hline 25.937 & 51.690 & 8.515 & 234.037 \\
\hline 25.925 & 51.438 & 8.561 & 236.767 \\
\hline 25.241 & 51.335 & 8.585 & 241.542 \\
\hline 26.025 & 51.891 & 8.428 & 240.437 \\
\hline 25.866 & 51.771 & 8.486 & 237.716 \\
\hline 26.073 & 51.737 & 8.449 & 238.125 \\
\hline 26.082 & 51.940 & 8.472 & 239.216 \\
\hline 25.978 & 51.644 & 8.541 & 240.456 \\
\hline 25.368 & 51.586 & 8.539 & 239.011 \\
\hline 26.818 & 51.881 & 8.441 & 239.726 \\
\hline 27.221 & 51.695 & 8.321 & 251.413 \\
\hline 27.173 & 52.057 & 8.324 & 252.674 \\
\hline 26.992 & 51.944 & 8.495 & 252.337 \\
\hline 27.048 & 51.918 & 8.451 & 252.374 \\
\hline 26.174 & 51.621 & 8.539 & 252.816 \\
\hline
\end{tabular}

The relationship with temperature is seen to be consistent throughout the deployment duration and also confirms the temperature relation theories explained earlier in this paper. Scatter plot results of 30 days trial at Node-3 (Sigatoka coastal water) are shown in Figure 16 which shows that the conductivity and ORP maintain a linear positive co-relationship with temperature but $\mathrm{pH}$ showed a linear negative co-relationship with temperature change that again validates SWQMS reliability. 

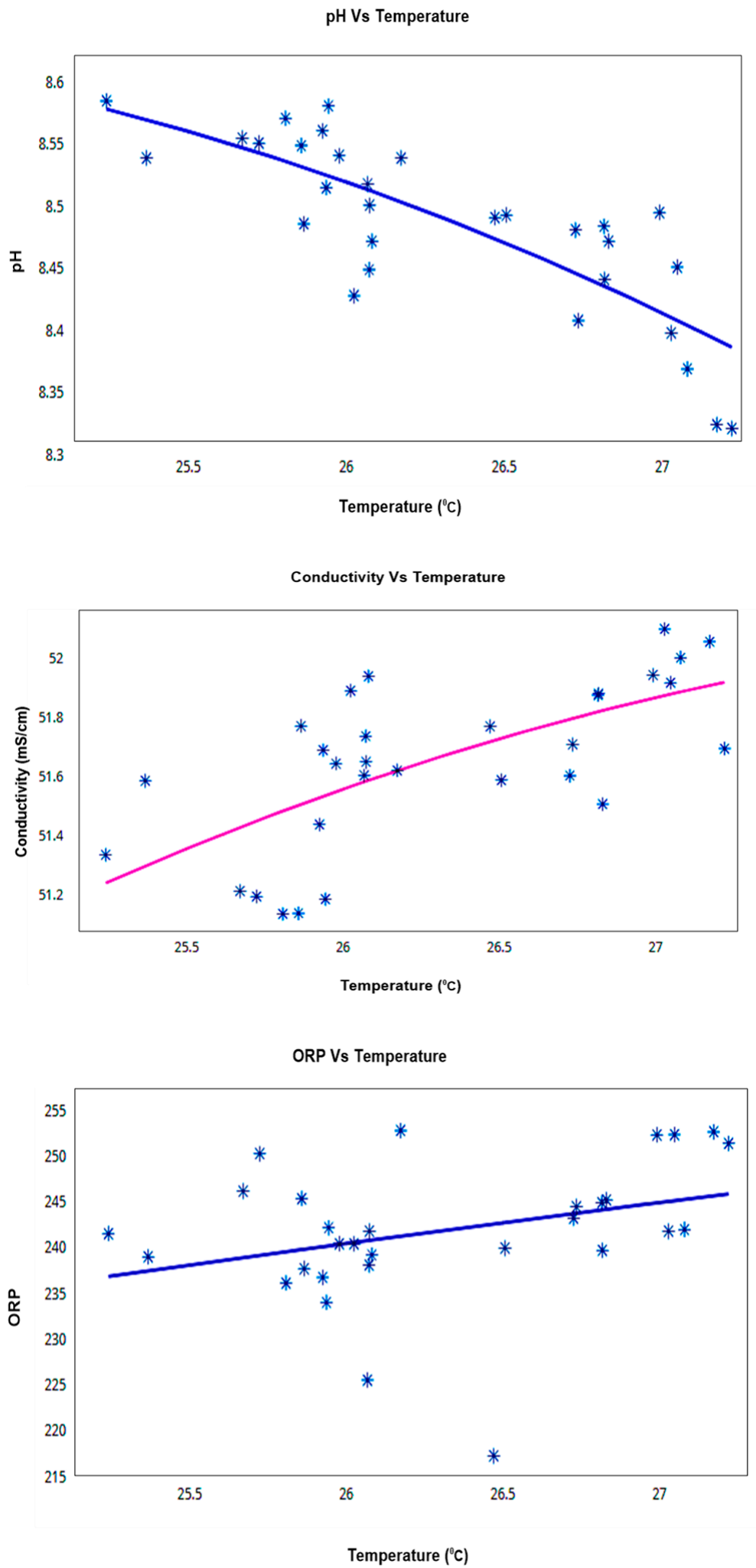

Figure 16. Temperature vs. other KPI Co-Relation Graphs for the 30 days trial (Node-3; Sigatoka coastal water). 
Table 9. Correlation of Daily Average KPI Data for a month for all sources.

\begin{tabular}{cccc}
\hline & \multicolumn{3}{c}{ Temperature Versus } \\
\hline Type of Water & Conductivity & pH & ORP \\
\hline & $r(p$-Value $)$ & $r(p$-Value $)$ & $r(p$-Value $)$ \\
\hline Coastal & $0.67^{* * *}(<0.001)$ & $-0.57^{* * *}(0.001)$ & $0.32(0.083)$ \\
Creek & $0.67^{* * *}(<0.001)$ & $-0.57^{* * *}(0.001)$ & $0.20(0.298)$ \\
Marine & $0.67^{* * *}(<0.001)$ & $-0.57^{* * *}(0.001)$ & $0.32(0.083)$ \\
River & $0.67^{* * *}(<0.001)$ & $-0.57^{* * *}(0.001)$ & $0.32(0.083)$ \\
Tap & $0.67^{* * *}(<0.001)$ & $-0.57^{* * *}(0.001)$ & $0.32(0.083)$ \\
\hline \multicolumn{4}{c}{ * Significant at $5 \%,{ }^{* *}$ Significant at $\%^{* * *}$ Significant at $0.1 \%}$.
\end{tabular}

\section{Conclusions}

In the SWQMS, sensor data has been interfaced with GIS, and four (04) different sources of water samples were monitored in real-time measuring four (04) KPIs in this case study conducted in the Fiji Islands. This paper also presents the use of REs to supply the power for the SWQMS. Finally, the developed system has been tested and validated based on a Case Study for Fijian surface water. The data obtained for tap water are consistent with the FNDWQS and therefore increases confidence in the reliability and accuracy of the measurements. In addition, the daily measurements for a month and diurnal data show very little variability, which re-affirms the reproducibility of the data and rules out any sensor fouling in field conditions for a month. The sensors were calibrated before deployment, but for future work it is imperative for external verification and validation of sensors to be undertaken. Water from different sources (creek, sea, river, and tap) were studied and the correlation between all the KPIs was observed utilizing several nodes.

The system demonstrated its usefulness by providing precise and reliable data/information throughout the experiment. SWQMS with GIS platforms used to monitor water quality in real-time provided a suitable answer for several PICs to improve the performance of the water management system. Although all of this information is currently not available in the public domain, over the next several years the SWQMS for Fiji Islands will continue to improve its public web maps and query tools to provide this data/information to the public, watershed stakeholders, and state and local governments. Consequently, SWQMS for Fiji Islands will better inform decisions to check, control, and reduce water pollution in the country. SWQMS is a unique technology designed to provide high-quality water parameter monitoring using renewable (PV) energy for the Pacific nations.

This SWQMS can be integrated with a cloud computing system for robust water quality monitoring in the future with a few more sensors added for DO, salinity, and nitrate. This designed SWQMS can be connected to the live cloud server with the help of the Internet of Things (IoT) and can access necessary information in real-time to effectively maintain water quality.

Author Contributions: K.A.M.: Ideas; formulation or evolution of overarching research goals and aims. F.R.I.: Conducting a research and investigation process, specifically performing the experiments, or data/evidence collection. R.H.: Acquisition of support for the project leading to this publication, plus organizing the manuscript. M.G.M.K.: Application of statistical, mathematical, computational, or other formal techniques to analyze or synthesize study data. A.N.P.: Conducting a research and investigation process, specifically performing the experiments, or data/evidence collection. H.H.: Conducting a research and investigation process, specifically performing the experiments, or data/evidence collection. R.R.M.: Conducting a research and investigation process, specifically performing the experiments, or data/evidence collection. F.S.M.: Management activities to annotate (produce metadata), scrub data and maintain research data for initial use and later re-use.

Funding: This research received no external funding.

Conflicts of Interest: No conflict of interest. 


\section{References}

1. Jenkins, J.O. Organisational arrangements and drinking water quality. Water Sci. Technol. Water Supply 2010, 10, 227-241. [CrossRef]

2. Shrestha, S.; Kazama, F. Assessment of surface water quality using multivariate statistical techniques: A case study of the Fuji river basin. JPN. Environ. Model. Softw. 2007, 4, 464-475. [CrossRef]

3. Ministry of Health, Fiji Island. Fiji National Drinking Water Quality Standards; Ministry of Health: Suva, Fiji, 2005.

4. Costa, D.; Burlando, P.; Priadi, C. The importance of integrated solutions to flooding and water quality problems in the tropical megacity of Jakarta. Sustain. Cities Soc. 2016, 1, 199-209. [CrossRef]

5. Khan, S.; Kordek, G. Coal Seam Gas: Produced Water and Solids. Report Commissioned for the Independent Review of Coal Seam Gas Activities in NSW; The NSW Chief Scientist \& Engineer; School of Civil Environmental Engineering, The University of New South Wales: Sydney, Australia, 2014.

6. Bichai, F.; Ashbolt, N. Public health and water quality management in low-exposure storm water schemes: A critical review of regulatory frameworks and path forward. Sustain. Cities Soc. 2017, 1, 453-465. [CrossRef]

7. Atzori, L.; Iera, A.; Morabito, G. The internet of things: A survey. Comput. Netw. 2010, 54, $2787-2805$. [CrossRef]

8. Gallone, G.; Gueli, R.; Patti, A.; Tropea, A. Improving automatic control of complex water systems, using AI techniques: Design ofan expert component for the alarms analysis. Water Sci. Technol. Water Supply 2005, 4, 375-381. [CrossRef]

9. Jensen, O.; Wu, H. Urban water security indicators: Development and pilot. Environ. Sci. Policy 2018, 83, 33-45. [CrossRef]

10. Bateman, I.J.; Lovett, A.A.; Brainard, J.S. Applied Environmental Economics: A GIS Approach to Cost-Benefit Analysis; Cambridge University Press: Cambridge, UK, 2003.

11. Takada, T.; Kashiyama, K. Development of an accurate urbanmodeling system using CAD/GIS data for atmosphere environmental simulation. IEEE Tsinghua Sci. Technol. 2008, 13, 412-417. [CrossRef]

12. Fang, S.; Da Xu, L.; Zhu, Y.; Ahati, J.; Pei, H.; Yan, J.; Liu, Z. An integrated system for regional environmental monitoring and management based on internet of things. IEEE Trans. Ind. Inform. 2014, 10, 1596-14605. [CrossRef]

13. Fiji Bureau of Statistics (FBS). Population Censuses and Surveys. 2009. Available online: http://www.statsfiji. gov.fj/index.php/census-and-surveys (accessed on 11 September 2017).

14. Wilde, F. Temperature 6.1. In USGS Field Manual. 2006. Available online: http://water.usgs.gov/owq/ FieldManual/Chapter6/6.1_ver2.pdf (accessed on 15 May 2019).

15. World Water Monitoring Challenge (WWMC), U.S. Department of the Interior. U.S. Geological Survey. 2016. Available online: https://water.usgs.gov/edu/temperature.html (accessed on 15 May 2019).

16. James, C.N.; Copeland, R.; Lytle, D.A. Relationships between oxidation- reduction potential, oxidant, and $\mathrm{pH}$ in drinking water. In Proceedings of the AWWA Water Quality Technology Conference, San Antonio, TX, USA, 14-18 November 2004.

17. Zhai, J.; Zhu, J.; He, Q.; Ning, K.; Xiao, H. variation of Dissolved oxygen and redox potential and their correlations with microbial population alond novel horizontal subsurface flow wetland. J. Environ. Technol. 2012, 33, 1999-2006. [CrossRef] [PubMed]

18. World Health Organization (WHO). Report on Drinking Water Quality Surveillance and Safety; Regional Office for the Western Pacific: Nadi, Fiji, 2001.

19. Islam, F.R.; Mamun, K.A. GIS based water quality monitoring system in pacific coastal area: A case study for Fiji. In Proceedings of the IEEE 2nd Asia-Pacific World Congress on Computer Science and Engineering (APWC on CSE), Nadi, Fiji, 2-4 December 2015; pp. 1-7.

20. Prasad, A.N.; Mamun, K.A.; Islam, F.R.; Haqva, H. Smart Water Quality Monitoring System. In Proceedings of the IEEE 2nd Asia-Pacific World Congress on Computer Science and Engineering (APWC on CSE), Nadi, Fiji, 2-4 December 2015.

21. The Pacific Ocean. Available online: http://www.bluebirdelectric.net/oceanography/pacificocean.htm (accessed on 15 May 2019).

22. Fondriest Environmental, Inc. Water Temperature. Fundamentals of Environmental Measurements. 2014. Available online: http://www.fondriest.com/environmentalmeasurements/parameters/water-quality/watertemperature (accessed on 15 May 2019). 
23. Libelium. Waspmote Datasheet. 2016. Available online: http://www.libelium.com/downloads/ documentation/waspmote_datasheet.pdf (accessed on 15 May 2019).

24. Islam, F.R.; Pota, H.R. Design a PV-AF system using V2Gtechnology to improve power quality. In Proceedings of the IEEE 37th Annual Conference on IEEE Industrial Electronics Society, Melbourne, Australia, 7-10 November 2011; pp. 861-866.

25. Islam, F.R.; Pota, H.R. Impact of Dynamic PHEV Load on Photovoltaic System. Int. J. Electr. Comput. Eng. 2012, 2088-8708. [CrossRef]

26. Yu-Kun, H.; Chun-Hui, Z.; Yu-Chung, H. A GIS-based waterdistribution model for Zhengzhou city, China. Water Sci. Technol. Water Supply 2011, 11, 497-503. [CrossRef]

27. Huang, B.; Jiang, B.; Li, H. An integration of GIS, virtual reality and the Internet for visualization, analysis and exploration of spatial data. Int. J. Geogr. Inf. Sci. 2001, 15, 439-456. [CrossRef]

28. Gabbar, H.A.; Bower, L.; Pandya, D.; Agarwal, A.; Tomal, M.U.; Islam, F.R. Resilient micro energy grids with gas-power and renewable technologies. In Proceedings of the IEEE International Conference on Power Engineering and Renewable Energy (ICPERE), Bali, Indonesia, 9-11 December 2014; pp. 1-6.

29. Brown, W. Kinetic vs. Thermal Energy. In Ask A Scientist; 1999. Available online: http://www.newton.dep. anl.gov/askasci/chem99/chem99045.htm (accessed on 15 May 2019).

30. Marion, G.M.; Millero, F.J.; Camoes, M.F.; Spitzer, F.; Fiestal, R.; Chen, C.-T.A. pH of seawater. Mar. Chem. 2011, 126, 89-96. [CrossRef]

31. SPREP. Fiji's State of Environment Report 2013; SPREP: Apia, Samoa, 2014; pp. 63-64.

32. Anna, F.R. Correlation between Conductivity and total Dissolved solids in various type of water: A review. IOP Conf. Ser. Earth Environ. Sci. 2018, 118, 012019.

33. Suslow, T.V. Oxidation-Reduction Potential (ORP) for Water Disinfection Monitoring, Control, and Documentation; University of California Division of Agriculture and Natural Resources: Davis, CA, USA, 2004.

(C) 2019 by the authors. Licensee MDPI, Basel, Switzerland. This article is an open access article distributed under the terms and conditions of the Creative Commons Attribution (CC BY) license (http://creativecommons.org/licenses/by/4.0/). 